\title{
Opportunistic feeding by house-dwelling geckos: does this make them more successful invaders?
}

\author{
ROBBIE WETERINGS ${ }^{1 *} \&$ PREEYAPORN WETERINGS ${ }^{1}$ \\ ${ }^{1}$ Cat Drop Foundation, Drachten, Netherlands \\ *Corresponding author e-mail: robbie.weterings@gmail.com
}

\begin{abstract}
Various species of 'house' gecko are found in and around buildings, where they can be observed feeding opportunistically on the insects attracted to artificial lights. Most of the species are considered strict insectivores. Nevertheless, there have been several recently published observations of 'house' geckos feeding on non-insect food. In order to assess how common this behaviour is among geckos worldwide, we offered an online questionnaire to ecologists and herpetologists. Of the 74 observations received, most reported Hemidactylus frenatus, H. platyurus and Gehyra mutilata feeding on rice, bread, fruits, vegetables, dog food or chocolate cream, taken from tables, plates, and garbage bins. This opportunistic feeding behaviour is much more common than previously thought and is perpetrated by species considered to be highly invasive, possibly contributing to their success as invaders.
\end{abstract}

\section{INTRODUCTION}

Sats everal gecko species (e.g. Hemidactylus frenatus and Gehyra mutilata) are often found in and around houses. These, so-called 'house' geckos, are very well adapted to urban life and are often observed feeding opportunistically on insects attracted to artificial lights at night (Tkaczenko et al., 2014). This provides them an easily accessible food source in locations generally lacking predators. In these conditions they reach higher densities in urban settings in comparison to their natural habitats (Weterings et al., 2018; Perry \& Fisher, 2006).

Besides this interesting adaptation, common insectivorous gecko species have been reported recently to feed on food other than insects (Weterings, 2017; Weterings \& Weterings, 2018; Tanalgo \& Hughes, 2017). For example, Hemidactylus platyurus and $H$. frenatus were observed feeding on rice in a bin (Weterings, 2017) and Gekko monarchus feeding on bread from a plastic bag (Weterings \& Weterings, 2018). To get an impression of how common this opportunistic feeding behaviour is among various insectivorous house-dwelling gecko species, we undertook an internet-based survey with ecologists, herpetologists and reptile enthusiasts that is reported here.

\section{METHODS}

We developed a short online questionnaire that participants could complete when they observed a gecko feeding on noninsect foods. It consisted of a short introduction to ensure that only non-insect foods were recorded followed by four questions:

1. Where did the gecko feed?
a. In a garbage bin
b. On a table
c. On dirty dishes
d. Other...

2. What did the gecko consume?
a. Insects or other invertebrates
b. Fruit or vegetables
c. Rice
d. Bread
e. Eggs
f. Unsure
g. Other...

3. What species did you observe feeding on non-insect food items?
a. Asian house gecko (Hemidactylus frenatus)
b. Mediterranean house gecko (H. turcicus)
c. Tropical house gecko (H. mabouia)
d. Flat-tailed house gecko (H. platyurus)
e. Brooke's house gecko (H. brookii)
f. Indo-Pacific gecko (H. garnotii)
g. Common four-clawed gecko (G. mutilata)
h. Other unknown Hemidactylus species
i. Not sure what species
j. Others...

4. Where did you make the observations?

4.1 Locality (village, town, park, research station...)

4.2 District/County

4.3 Province/State

4.4 Country

The first three questions were multiple-choice, however, participants were given the freedom to submit alternative responses. The third question was accompanied by photographs of the various common house gecko species.

The questionnaire was shared on the ECOLOG listserver, on www.fieldherpforum.com, and on several Facebook pages and groups including the Facebook groups of the Societas Europaea Herpetologica and HerpResearch among others. The results of the questionnaire were plotted using the GGPLOT2 (Wickham, 2009) library in RStudio v1.1.383 (RStudio, 2017) built on R v3.5.3 (R Development Team, 2019). 


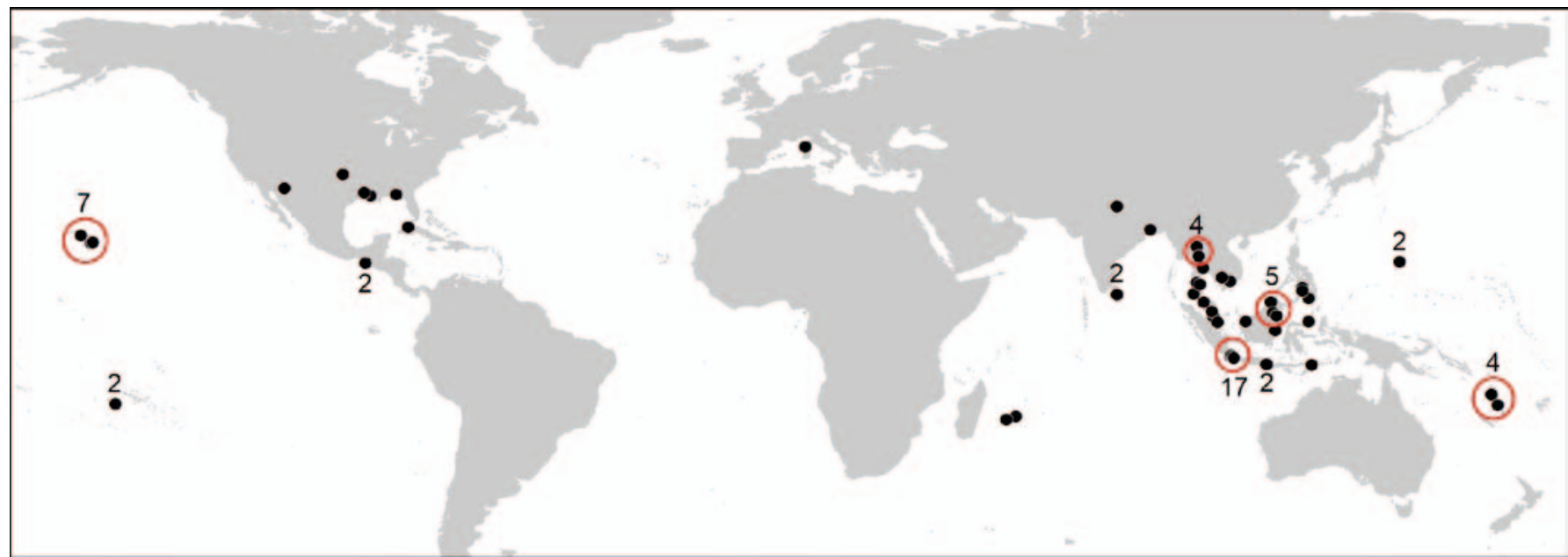

Figure 1. Map showing the location (black dots) were geckos were observed feeding on non-insect food. Circles show areas where the black dots overlap, numbers indicate the number of observations within a circle.
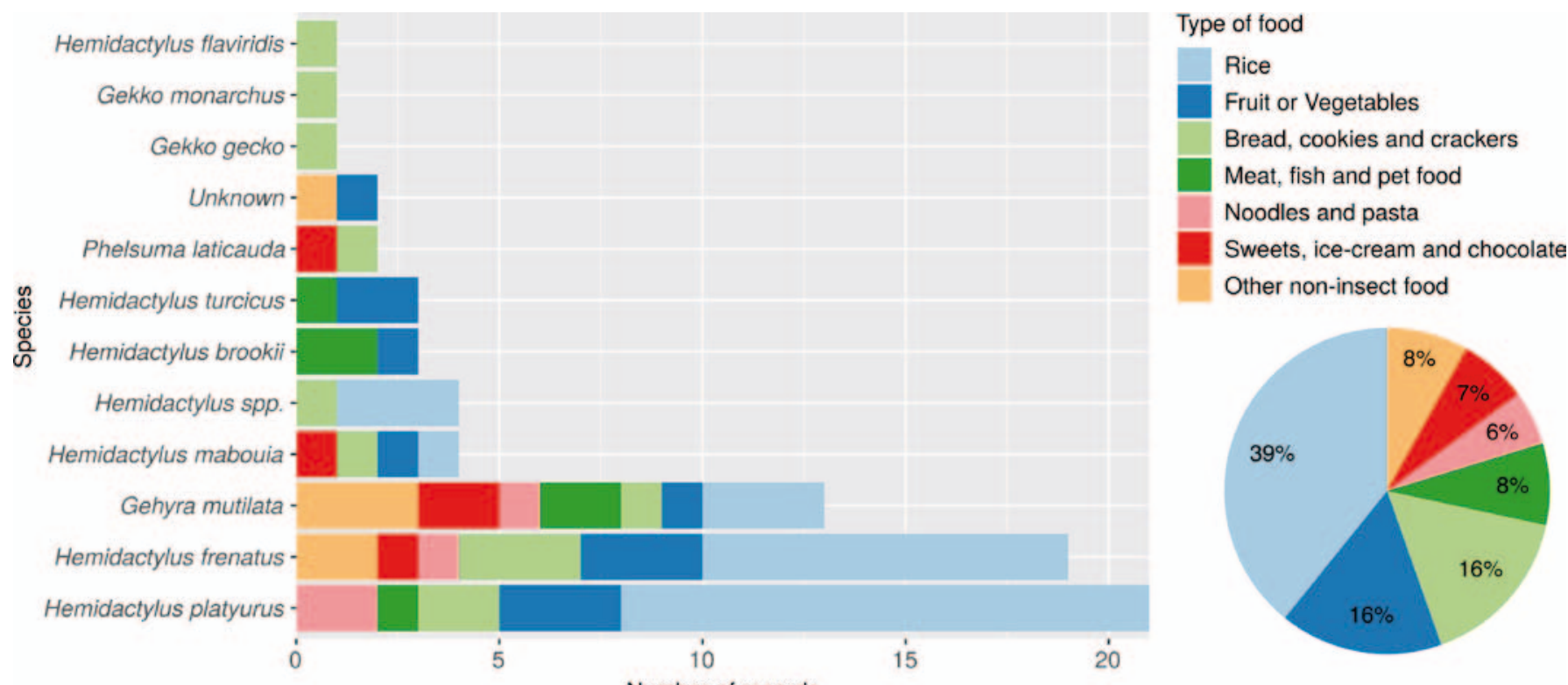

Figure 2. A bar chart showing the number of observations of non-insect food for different gecko species. The pie chart shows each food type as a percentage of all observations.

\section{RESULTS}

We received a total of 80 responses of which 74 included gecko feeding on non-insect foods. Most responses came from south-east Asia and the United States of America (Fig. 1). In total ten species, which are considered insectivorous, were observed feeding on non-insect foods. The species $H$. platyurus, $H$. frenatus and $G$. mutilata accounted for $72 \%$ of the observations (Fig 2). The most commonly consumed noninsect food was cooked rice followed by fruit and vegetables and baked goods such as bread, cookies and crackers.

Some geckos were observed feeding on very particular food items. Phelsuma laticauda was, for example, observed feeding on an alcoholic tropical drink in Hawaii. Gehyra mutilata was observed eating garlic sauce from a bowl on a table top in Indonesia. On Vanuatu, a tropical paradise in the Pacific Ocean, $H$. frenatus was seen eating chocolate cream from a cake. Geckos were mostly observed feeding on the alternative food items on table tops ( $41 \%$ ), followed by dirty dishes (11\%), floors (9\%), garbage bins (7\%), walls (3\%) and a variety of other locations (30\%).

\section{DISCUSSION}

Our survey shows that opportunistic feeding in geckos is more common than the incidental reports suggest (Weterings, 2017; Tanalgo \& Hughes, 2017; Weterings \& Weterings, 2018). Such feeding has been recorded for all common invasive house geckos, except for Hemidactylus garnotii, and also from other house-dwelling gecko species that are not considered invasive. These observations have largely come from south-east Asia, a direct consequence of the professional network of the authors, consequently Africa and South America are considered to be under-represented.

There have been several dietary studies of house geckos including $H$. frenatus, $H$. mabouia, $H$. platyurus, $G$ mutilata and H. turcicus (Tyler, 1961; Saenz, 1996; Ramires \& Fraguas, 2004; Rocha \& Anjos, 2007; Diaz Perez et al., 2012; Tkaczenko 
et al., 2014; Barragán-Ramírez et al., 2015). In most of these studies, only insects were found in the diet although a few mention the presence of vegetal items within the stomach content (Iturriaga \& Marrero 2013; Barragán-Ramírez et al., 2015). In these cases, vegetal content was considered to be ingested accidentally, i.e. not part of the gecko's diet. However, existing research into house gecko diet may be biased towards recording insects for two reasons. First, when gecko foraging is observed this is often on walls where artificial lighting attracts large numbers of insects (Tkaczenko et al., 2014; Aowpol et al., 2006). Second, when examining stomach contents, it is relatively easy to identify the hard exoskeleton of arthropods but identifying fruit, vegetables, ice-cream or dog-food from the stomach-gunk is often impossible.

Opportunistic behaviours and adaptability to new and changing environmental conditions facilitate the rapid colonisation of species in new habitats (Whitney \& Gabler 2008, Chapple et al., 2012). Many of the gecko species reported in this study can be found in regions outside their native range and so are considered highly invasive (Weterings \& Vetter, 2017). The opportunistic feeding behaviour that is observed in these gecko species may be an important factor in successful invasion. During periods of low insect abundance, for example during accidental transport (stowaways), these species are able to eat other foods so allowing them to survive.

\section{REFERENCES}

Aowphol, A., Thirakhupt, K., Nabhitabhata, J. \& Voris, H. K. (2006). Foraging ecology of the Tokay gecko Gekko gecko in a residential area in Thailand. Amphibia-Reptilia 27: 491-503.

Barragán-Ramírez, J. L., Reyes-Luis, O. E., de Jesús AscencioArrayga, J., Navarrete-Heredia, J. L., \& Vásquez-Bolaños, M. (2015). Diet and reproductive aspects of the exotic gecko Gehyra mutilata (Wiegmann, 1834) (Sauria: Gekkonidae) in the urban area of Chapala, Jalisco, Mexico. Acta Zoológica Mexicana 3: 67-71.

Chapple, D., Simmonds, S. M. \& Wong, B. B. M. (2012). Can behavioral and personality traits influence the success of unintentional species introductions? Trends in Ecology \& Evolution 27: 57-64.

Diaz Perez, J. A., Davila Suarez, J. A., Alvarez Garcia, D. M. \& Sampedro Marin, A. C. (2012). Dieta de Hemidactylus frenatus (Sauria: Gekkonidae) en un area urbana de la region Caribe Colombiana. Acta Zoologica Mexicana 28: 613-616.

Iturriaga, M. \& Marrero, R. (2013). Feeding ecology of the Tropical House Gecko Hemidactylus mabouia (Sauria: Gekkonidae) during the dry season in Havana, Cuba. Herpetology Notes 6: 11-17.

Perry, G. \& Fisher, R. (2006). Night lights and reptiles: observed and potential effects. In: Ecological Consequences of Artificial Night Lighting 169-191 pp. (C. Rich, T. Longcore, Eds.). Island Press, Washington.
Ramires, E.N. \& Fraguas, G.M. (2004). Tropical house gecko (Hemidactylus mabouia) predation on brown spiders (Loxosceles intermedia). Journal of Venomous Animals and Toxins including Tropical Diseases 10: 185-190.

R Development Core Team (2019). R: A language and environment for statistical computing. R Foundation for Statistical Computing, Vienna, Austria.

Rocha, C. F. D. \& Anjos, L. (2007). Feeding ecology of a nocturnal invasive alien lizard species, Hemidactylus mabouia Moreau de Jonnès, 1818 (Gekkonidae), living in an outcrop rocky area in southeastern Brazil. Revista Brasleira de Biologia 67: 485-91.

Rstudio (2017). RStudio: integrated development environment for $\mathrm{R}$ (Version v1.1.383). Boston, MA.

Saenz, D. (1996). Dietary overview of Hemidactylus turcicus with possible implications of food partitioning. Journal of Herpetology 30: 461-466.

Tanalgo, K. C. \& Hughes, A. (2017). First evidence of nectarivory by four-clawed gecko, Gehyra mutilata (Wiegmann, 1834) (Squamata: Gekkonidae) on a bat-pollinated Calabash tree (Crescentia cujete L.) (Bignoniaceae) in Southcentral Mindanao, Philippines. Herpetology Notes 10: 493-496.

Tkaczenko, G. K., Fischer, A. C. \& Weterings, R. (2014). Prey preference of the common house geckos Hemidactylus frenatus and Hemidactylus platyurus. Herpetology Notes 7: 483-488.

Tyler, M. J. (1961). On the diet and feeding habits of Hemidactylus frenatus (Dumeril and Bibron) (Reptilia; Gekkonidae) at Rangoon, Burma. Transactions of the Royal Society of South Australia 84: 45-49.

Weterings, R. \& Weterings, P. (2018). Observations of the warty house gecko, Gekko monarchus (Schlegel, 1836), feeding on bread. Herpetology Notes 11: 319-320.

Weterings, R. (2017). Observations of an opportunistic feeding strategy in flat-tailed house geckos (Hemidactylus platyurus) living in buildings. Herpetology Notes 10: 133135.

Weterings, R. \& Vetter, K. C. (2017). Invasive house geckos (Hemidactylus spp.): their current, potential and future distribution. Current Zoology 64: 559-573.

Weterings, R., Umponstira, C. \& Buckley, H. L. (2018) Landscape variation influences trophic cascades in dengue vector food webs. Science Advances 4: eaap9534

Whitney, K. D. \& Gabler, C. A. (2008). Rapid evolution in introduced species, 'invasive traits' and recipient communities: challenges for predicting invasive potential. Diversity and Distributions 14: 569-580.

Wickham, H. (2009) GGPLOT2: Elegant Graphics for Data Analysis. Springer-Verlag, New York, ISBN 978-0-38798140-6, pp. 216.

Accepted: 6 August 2019 